\title{
Editorial
}

\section{Ivan Giongo PhD}

Assistant Professor, Department of Civil, Environmental and Mechanical Engineering, University of Trento, Trento, Italy

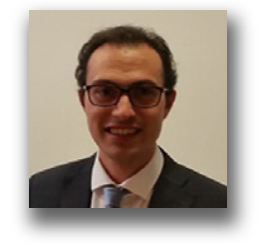

The July issue of Structures and Buildings features six stimulating papers covering a wide range of topics in the field of structural and building engineering. Despite the variety of themes explored, all the papers have a common trait in supplementing new theories and solutions with solid evidence. Therefore, it is a pleasure for me to introduce such papers to you.

The first two papers deal with topics related to the mitigation of seismic vulnerability of buildings. In the opening paper, Bhaiya et al., (2020) report on an interesting research focused on assessing the effectiveness of a peculiar hybrid seismic control strategy that combines tuned mass dampers (TMDs) with magnetorheological (MR) dampers. In the paper, the authors also propose a new algorithm, named velocity tracking control algorithm, to be used with MR dampers for 'partially observed' semi-active control. A six-story and a ten-storey onebay concrete frames are adopted as case-study structures to evaluate and compare alternative configurations of mixed control devices. The frames are subjected to ground motions registered from far-field and near-field natural events. Two TMD mass ratios (i.e. $5 \%$ and $10 \%$ ) are considered in the analyses by the authors. The performance of the hybrid control configurations, measured with reference to the top-floor displacement, maximum inter-storey drift, and base shear, is benchmarked against the performance of control strategies based on MR dampers only. The authors conclude that the most effective among the hybrid control strategies appears to be that where a single MR damper is working in series with the TMD located at the frame top-level. An interesting 'saturation effect' in the response reduction is observed in the configurations with just MR dampers when the number of dampers exceeds three.

The second paper, by Mohammadrezapour and Danesh (2020), presents an experimental and numerical study on linkto-column connections in eccentrically braced frames (EBFs) with long links. Specifically, the authors propose to use topand seat-angle with double web-angle bolted connections to ensure that the link-beam can develop its full plasticity, as opposed to evidence reported in literature where linkto-column joints in EBFs often fail prior to reaching the desired inelastic rotation. A full-scale specimen, where the link-to column bolted connection has been designed to be semi-rigid (i.e. the connection capacity is smaller than the beam plastic moment), is subjected to cyclic loading up to a measured inelastic rotation twice the value required by the relevant standard code. The good performance shown by the experimental testing is matched by the results from the numerical finite element simulations where the influence of design parameters such as bolt diameter and angle thickness is evaluated through non-linear static analyses.

In order to guarantee the seismic safety of constructions, all building components have to be properly designed to sustain earthquake loading. This concept applies not just to loadbearing elements but also to non-structural components such as façade claddings. Because of its aesthetic appearance, durability, and cost-effectiveness, stone cladding is highly appreciated by designers and owners. However, being stone cladding quite heavy, its failure due to the combined effect of gravity and inertia forces is characterized by potentially disastrous consequences as evidenced by cases of failure reported in the literature. The third paper, by Huang and Lu (2020), studies the load-bearing capacity of "dowel pin anchorage" for fixing granite cladding panels. The influence of design parameters such as the pin diameter and the presence of the plastic sleeve is examined via monotonic experimental testing. The test outcomes show that increasing the pin diameter from $5 \mathrm{~mm}$ to $8 \mathrm{~mm}$ negatively influences the connection capacity and its ability to develop plastic deformations due to brittle failure of the granite surrounding the pin. To provide further insight on the failure mode of the various anchorage configurations, finite element modelling is performed.

The focus of the next paper is also placed on the topic of facades. In the work by Ahmadi and Reisi (2020), a testing campaign on concrete and fired facing bricks is presented. Lightweight expanded clay aggregate (Leca) concrete facing blocks are tested in compression, in bending and under freezeand-thaw cycles to determine their mechanical properties and durability. Facing blocks with different density, due to variation in the Leca content, are considered in the study. The test 
results from the Leca concrete blocks are compared with the performance obtained by the authors from clay, shale and refractory facing bricks, also characterized by different densities. For any density level, the Leca concrete blocks exhibit higher compressive and flexural strength than the clay, shale and refractory bricks. As concerns freeze-and-thaw resistance, the authors report that all clay and shale facing brick specimens failed before 110 cycles, while Leca concrete and refractory facing bricks were capable of sustaining 150 cycles. Given their mechanical and durability performance, as well as their reduced cost, Leca concrete facing blocks represent a valid alternative to "traditional" facing bricks.

The fifth and sixth papers concentrate on issues related to columns under vertical loading. Truong and Choi (2020) propose a new strength-based approach to assess the punching capacity of concrete column footings. The model applies to squat footings with small shear span-to-depth ratios as well as to slender footings, both without transverse reinforcement. According to the model, the resisting mechanism is primarily influenced by the uncracked concrete in the compression zone located above the neutral axis. An iterative procedures permits to determine all the quantities necessary to calculate the punching shear capacity. The assumptions made by authors are validated against the experimental data from 171 tests available in the literature. The ratios between experimental and predicted strengths have a mean value of 0.92 with a coefficient of variation of $0 \cdot 147$, outperforming the accuracy of current design approaches recommended by recognised international standards such as ACI 318-14 (ACI, 2014) and KCI 2012 (KCI, 2012). The authors however, point out that for the model to be adopted in the design practice further simplifications in calculating the required parameters will have to be provided, together with safety factors that guarantee an adequate level of conservativeness.

In the last paper, Ellobody et al., (2020) experimentally investigate the behaviour under compressive loading of stainless steel columns filled with steel-fibre-reinforced concrete (SFRC). The aim of the study is to supplement the research carried out previously by the authors with new data and thus further highlight the benefits ensuing from creating composite columns that couple stainless steel tubular sections with an SFRC core. The experimental campaign sees 23 tests performed on rectangular and circular columns. The test set includes hollow columns and columns that are filled with high-strength plain concrete, to be used as benchmarks. The results show that the use of an SFRC core generates promising performance in terms of both column capacity and ductility. The test outcomes are then compared with the capacity values calculated according to Eurocode 4 (BSI, 2004) provisions. From the comparison, it emerges that Eurocode 4 can predict the load bearing capacity of stainless steel columns filled with SFRC with good accuracy, despite a certain degree of non-conservativeness in the case of columns filled with plain concrete.

I am hopeful that you will find this month's issue of Structures and Buildings informative and inspiring. As usual, discussions or comments on any of the papers are welcomed; instructions on how to contribute can be found at the papers' last page.

\section{REFERENCES}

ACl (American Concrete Institute) (2014) ACI 318-14: Building code requirement for structure concrete. ACI, Farmington Hills, MI, USA

Ahmadi SF and Reisi M (2020) Comparison of mechanical and durability properties of concrete and fired facing bricks. Proceedings of the Institution of Civil Engineers - Structures and Buildings 173(7): 512-522, https://doi.org/10.1680/ jstbu.18.00144.

Bhaiya V, Bharti SD, Shrimali MK and Datta TK (2020) Hybrid seismic control of buildings using tuned mass and magnetorheological dampers. Proceedings of the Institution of Civil Engineers Structures and Buildings 173(7): 471-487. https://doi.org/ 10.1680/jstbu.18.00090.

BSI (2004) BS EN 1994-1-1, Eurocode 4: Design of composite steel and concrete structures - Part 1-1: general rules and rules for buildings. BSI, London, UK.

Ellobody E, Alfazari S, Alghafri W and Aladawi A (2020) Design and testing of stainless steel columns filled with steel-fibre-reinforced concrete. Proceedings of the Institution of Civil Engineers Structures and Buildings 173(7): 535-546. https://doi.org/ 10.1680/jstbu.18.00165.

Huang B and Lu W (2020) Load-bearing capacity testing of dowel pin anchorage in granite cladding. Proceedings of the Institution of Civil Engineers - Structures and Building 173(7): 501-511, https://doi.org/10.1680/jstbu.18.00059.

$\mathrm{KCl}$ (Korean Concrete Institute) (2012) KCI 2012: Design code of concrete structure. KCI, Seoul, Korea.

Mohammadrezapour E and Danesh F (2020) Experimental and numerical study of semi-rigid connection for long link-to-column joints. Proceedings of the Institution of Civil Engineers - Structures and Buildings 173(7): 488-500, https://doi.org/10.1680/ jstbu.18.00037.

Truong GT and Choi KK (2020) Punching strength of concrete footings based on the compression zone failure mechanism. Proceedings of the Institution of Civil Engineers - Structures and Buildings 173(7): 523-534, https://doi.org/10.1680/jstbu.17.00135. 